ORIGINAL ARTICLE

\title{
Elastic stable intramedullary nailing of midclavicular fractures in athletes
}

\author{
A Jubel, J Andermahr, H Bergmann, A Prokop, K E Rehm
}

See end of article for authors' affiliations

Correspondence to: Dr Jubel, Department of Traumatology, Hand and Reconstructive Surgery, University Hospital of Cologne, Kerpener Str 61, 50931 Cologne, Germany; axeliubel@ t-online.de

Accepted 16 June 2003

\begin{abstract}
Background: Intramedullary fixation of midclavicular fractures may be a better option than non-operative treatment for high performance/professional athletes because of the potential reduction in recovery time. Objectives: To evaluate the effectiveness of intramedullary fixation in high performance athletes and the time required to return to sporting activity.

Methods: Data were taken from a prospective study on intramedullary fixation techniques using the elastic stable Ti nail (TEN, Synthes) for the treatment of displaced midclavicular fractures, initiated in 1996. The patients in 12 cases were classified as high performance/professional athletes. These cases were used to evaluate the technique specifically in this population. Fractures were classified according to the Orthopaedic Trauma Association (OTA) system. Patients were evaluated before and after surgery for shoulder function and subjective pain. After the operation, radiological assessments documented fracture healing, and clinical outcomes scores were obtained. Time required to return to training and competition was documented.

Results: All fractures were transverse or oblique. Mean (SD) shoulder abduction increased from $36.3(8)^{\circ}$ before surgery to $154.2(17)^{\circ}$ afterwards $(p<0.001)$. Mean subjective pain score using a visual analogue scale (0-100) decreased from $71.7(18)$ points before surgery to $19.2(6)$ points $(p<0.001)$ three days after. There were no complications. Hospital stay averaged 2.9 (1) days. Mean delay to resumption of training was 5.9 (1) days, and to resumption of competition it was 16.8 (5) days. The mean Constant clinical outcomes score one year after hardware removal was 98.3 (2) points.

Conclusions: Intramedullary fixation of displaced midclavicular fracture was successful in terms of clinical outcome and rapid resumption of sporting activities. This treatment should be offered to athletes as an alternative to non-operative treatment.
\end{abstract}

O ne of the most commonly observed injuries in sport is fracture of the clavicle. ${ }^{1}$ Direct trauma, such as a fall on to the shoulder, is the typical mechanism of injury. ${ }^{2}$ Thus, participants in sports such as cycling, horse riding, Alpine skiing, and motor cycling are the most commonly affected. ${ }^{13-7}$ Some $70-80 \%$ of fractures involve the middle third of the bone. ${ }^{89}$ This type of injury is characterised by its good prognosis for healing and functional outcome. $^{21011}$ Therefore, non-operative treatment is the standard.

For high performance, professional athletes, a long recuperation is likely to result in considerable financial loss. Therefore, new treatment options for fractures of the clavicle are particularly important to these patients.

The aim of this study was to evaluate the outcome of a minimally invasive intramedullary surgical treatment for fractures of the middle third of the clavicle. Special emphasis was placed on recovery time, specifically on the time required by athletes to return to training and competition.

\section{METHODS}

The data presented here are from a prospective clinical study initiated in December 1996. Patients enrolled in the study initially presented with one or more of the following indications for surgical repair of a midclavicular fracture: (a) gross displacement of the fracture (shortening of more than $2 \mathrm{~cm}$ ); (b) accompanying injuries of the lower limbs; (c) multiple traumatic injuries; $(d)$ concurrent injuries of the scapula (floating shoulder). Owing to the good results achieved with these patients, ${ }^{12}$ from May 2000 onwards all patients with displaced midclavicular fractures were included. Patients older than 80 or younger than 10, as well as those with non-union or pathological fractures, were excluded.

This study presents the data of patients working as high performance or professional athletes.

\section{Surgical procedure}

Each patient was placed on a radiolucent operating table in the supine position. A skin incision of $1-2 \mathrm{~cm}$ was made just above the sternal end of the clavicle. About $1 \mathrm{~cm}$ distal to the sternoclavicular joint, a hole was drilled into the ventral cortex of the sternal end of the clavicle with a $2.5 \mathrm{~mm}$ drill and widened using an awl. The Ti nail (TEN; Synthes, Bochum, Germany), $2.0-3.5 \mathrm{~mm}$, was fixed in a universal chuck with a $\mathrm{T}$ handle. With oscillating movements, the surgeon advanced the unreamed Ti nail until it reached the fracture site. Here, the tip of the implant was used as a runner and prevented perforation of the opposite cortex. To ensure correct placement of the nail, fluoroscopic control was used for reduction and insertion of the nail into the lateral fragment. If closed reduction manoeuvres were unsuccessful, an accessory incision of 3-4 cm was made above the fracture site to enable direct manipulation of the fragments. Small AO reduction forceps were used to maintain reduction. The initial positions and soft tissue connections of additional comminuted fragments were maintained. The protruding end of the nail was cut off at the site of its insertion. Antibiotic prophylaxis was not used.

No immobilisation was performed after surgery. Patients were encouraged to move the arm subject to pain and to use it in daily activities. Before and after the operation, patients took $2 \times 50 \mathrm{mg}$ diclofenac daily to relieve pain. In cases of simple fracture (only two fragments), athletes were per- 

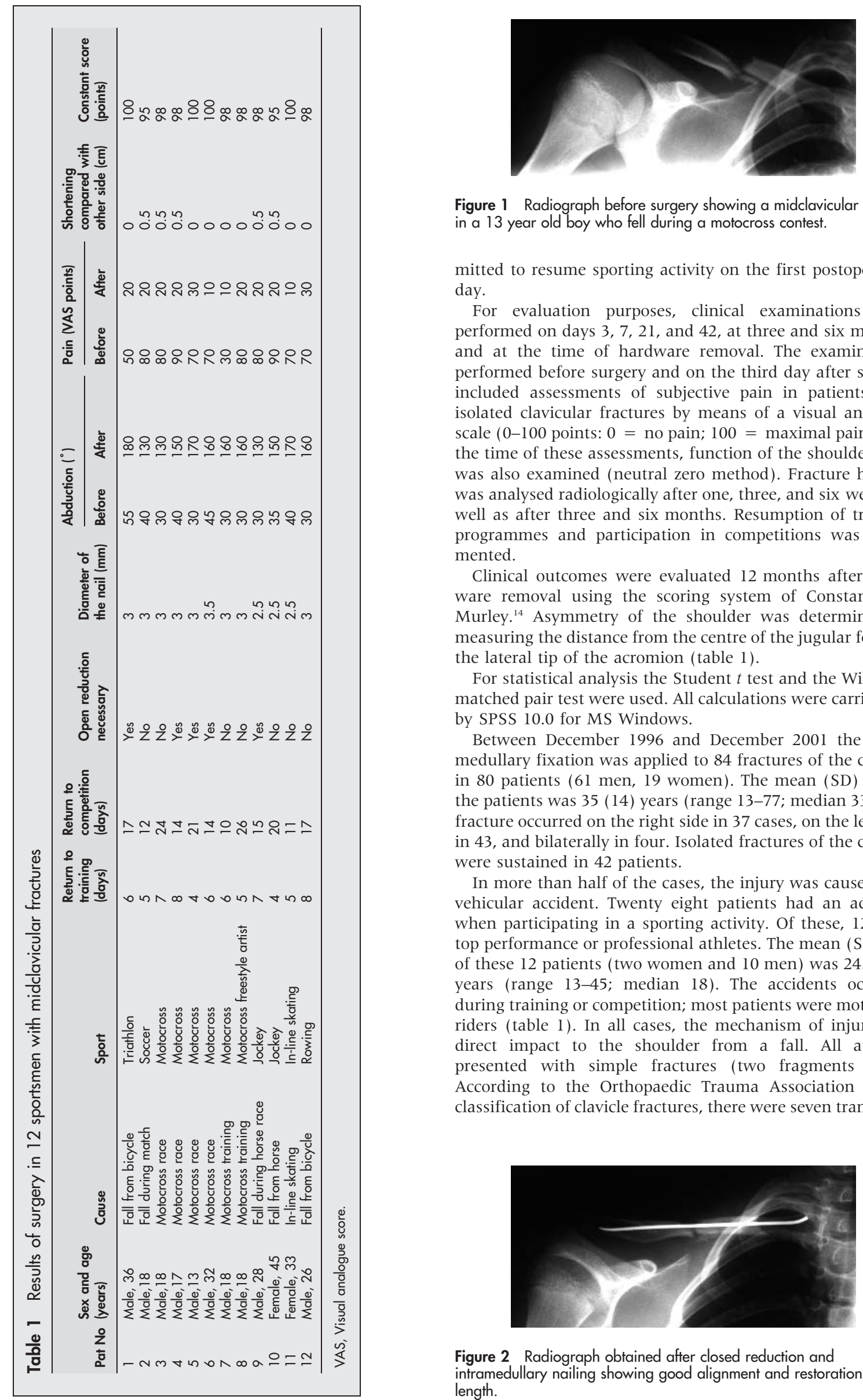

Figure 1 Radiograph before surgery showing a midclavicular fracture in a 13 year old boy who fell during a motocross contest.

mitted to resume sporting activity on the first postoperative day.

For evaluation purposes, clinical examinations were performed on days 3, 7, 21, and 42, at three and six months, and at the time of hardware removal. The examinations performed before surgery and on the third day after surgery included assessments of subjective pain in patients with isolated clavicular fractures by means of a visual analogue scale $(0-100$ points: $0=$ no pain; $100=$ maximal pain $) \cdot{ }^{13}$ At the time of these assessments, function of the shoulder joint was also examined (neutral zero method). Fracture healing was analysed radiologically after one, three, and six weeks as well as after three and six months. Resumption of training programmes and participation in competitions was documented.

Clinical outcomes were evaluated 12 months after hardware removal using the scoring system of Constant and Murley. ${ }^{14}$ Asymmetry of the shoulder was determined by measuring the distance from the centre of the jugular fossa to the lateral tip of the acromion (table 1).

For statistical analysis the Student $t$ test and the Wilcoxon matched pair test were used. All calculations were carried out by SPSS 10.0 for MS Windows.

Between December 1996 and December 2001 the intramedullary fixation was applied to 84 fractures of the clavicle in 80 patients (61 men, 19 women). The mean (SD) age of the patients was 35 (14) years (range 13-77; median 33). The fracture occurred on the right side in 37 cases, on the left side in 43 , and bilaterally in four. Isolated fractures of the clavicle were sustained in 42 patients.

In more than half of the cases, the injury was caused by a vehicular accident. Twenty eight patients had an accident when participating in a sporting activity. Of these, 12 were top performance or professional athletes. The mean (SD) age of these 12 patients (two women and 10 men) was 24.8 (10) years (range 13-45; median 18). The accidents occurred during training or competition; most patients were motocross riders (table 1 ). In all cases, the mechanism of injury was direct impact to the shoulder from a fall. All athletes presented with simple fractures (two fragments only). According to the Orthopaedic Trauma Association (OTA) classification of clavicle fractures, there were seven transverse

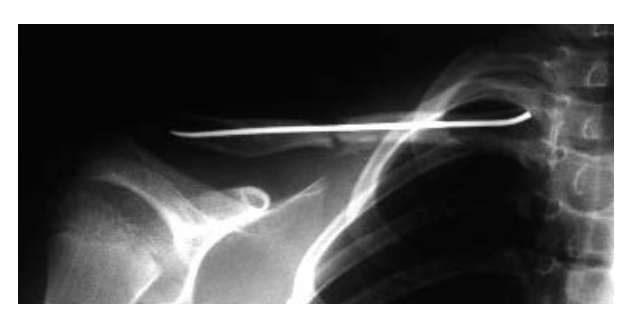

Figure 2 Radiograph obtained after closed reduction and intramedullary nailing showing good alignment and restoration of length. 


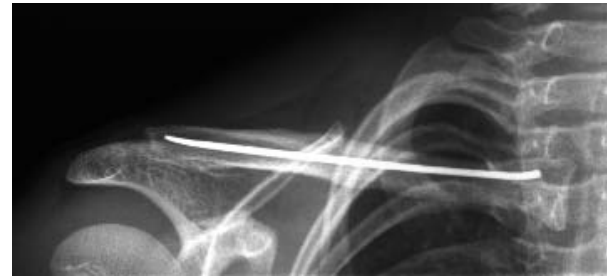

Figure 3 Radiograph obtained four months after surgery showing no implant displacement. The fracture is healed.

(06-A3), and five oblique (06-A2) fractures. In addition to the fractured clavicle, one cyclist had a minor head injury.

\section{RESULTS}

Operations were performed 4 (3) days (range 0-8, median 4) after the accident. Closed reduction manoeuvres were successfully applied to seven fractures. In five cases, an additional skin incision was necessary for satisfactory reduction. In most cases, a nail of $3 \mathrm{~mm}$ diameter could be used. For one large man, a nail of $3.5 \mathrm{~mm}$ diameter was applied. For the women and one small man, nails of $2.5 \mathrm{~mm}$ diameter were used. The mean duration of $x$ ray fluoroscopy during surgery was 3.5 minutes (range 0.2-7.4, median 3.5).

Before surgery, mean (SD) abduction of the shoulder joint was $36.3(8)^{\circ}$ (range 30-55, median 35); after surgery, it was $154.2(17)^{\circ}$ (range 130-180, median 160) $(\mathrm{p}<0.001)$. On a visual analogue scale, subjective pain before surgery was 71.7 (18) points (range 30-90, median 80). This was significantly $(\mathrm{p}<0.001)$ higher than on the third day after surgery: 19.2 (6) points (range 10-30, median 20). Similar findings were noted in the whole cohort of 80 patients in terms of shoulder function (range of motion) and subjective pain. Furthermore, in all 80 patients treated with this technique, there were no wound infections, implant displacements, or re-fractures.

The length of inpatient stay averaged 2.9 (1) days (range 1-6, median 2). The athletes resumed training 5.9 (1) days (range 4-8, median 6) after surgery. Participation in competition was resumed after 16.8 (5) days (range 10-26, median 15). All of the fractures healed. Of 84 fractures, only one non-union was observed.

The hardware was removed after 7.2 (2) months (range 410, median 6). The inpatient stay required for this procedure averaged 0.9 days (range $0-2$, median 1 ). In four patients, it was performed as an outpatient procedure, and one of these was performed under local anaesthesia.

Twelve months after implant removal, the mean (SD) measure on the Constant score was 98.3 (2) points (range $95-100$, median 99). For the total cohort of 80 patients, the Constant score averaged 96.2 (5) points.

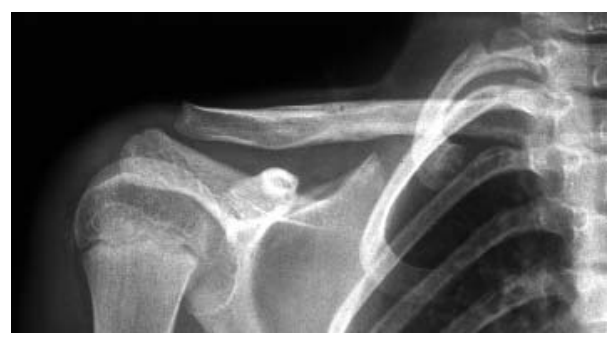

Figure 4 Radiograph obtained after hardware removal and five months after operation showing that there is no excessive callus formation and the shape of a normal clavicle is restored.

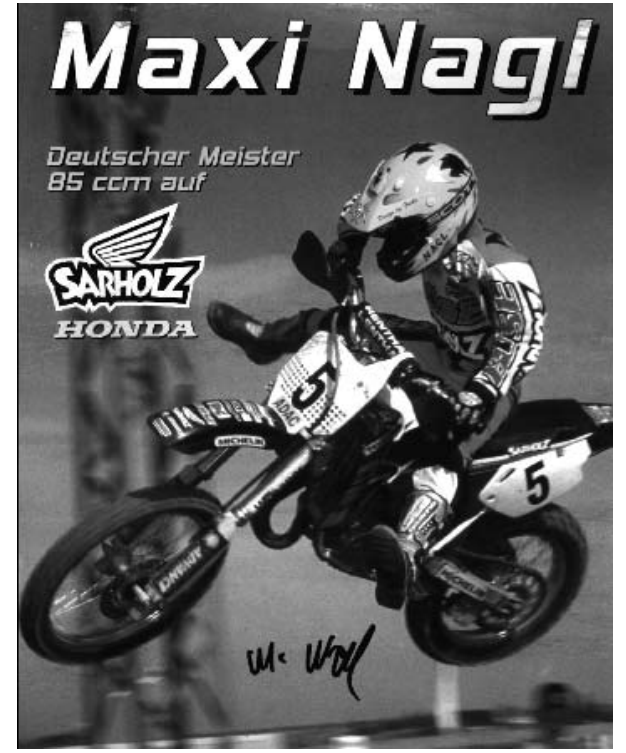

Figure 5 Photograph showing the boy jumping with his motorbike three weeks after the operation, when he won his division.

\section{DISCUSSION}

In leisure and high performance sports, fracture of the clavicle is one of the most commonly observed injuries. ${ }^{1}$ Standard treatment is application of a figure of eight harness for five to six weeks. ${ }^{15}{ }^{16}$ Rowe ${ }^{9}$ reported that midclavicular fractures in adults are often underrated with regard to pain and disability during the first three weeks. For high performance and professional athletes, this fracture is of major importance. The time required for the fracture to heal results in training delays, missed competitions, and, perhaps most important, financial loss.

There is some dispute about indications for surgery for fractures of the middle third of the clavicle. However, in the past, indications have been set very cautiously. ${ }^{17}$ Internal fixation using plates is the standard surgical procedure. ${ }^{18}$ The typical problems with this technique are: common hypertrophic or keloid scars, ${ }^{19}$ implant loosening, ${ }^{20}{ }^{21}$ non-union, ${ }^{22}$ and re-fracture after implant removal. ${ }^{20-22}$ Different modifications of $\mathrm{K}$ wire or nail fixation of the clavicle have been reported. ${ }^{23-27}$ In general, operative techniques have not been widely used to date because complication rates are higher than with conservative treatment. ${ }^{28}$ One problem encountered has been migration of the intramedullary implants. ${ }^{29}$ According to Schwarz and Leixnering, ${ }^{30}$ however, unsatisfactory results after intramedullary procedures are caused either by the use of wires that are insufficiently strong or long, or by inadequate reduction of the fracture.

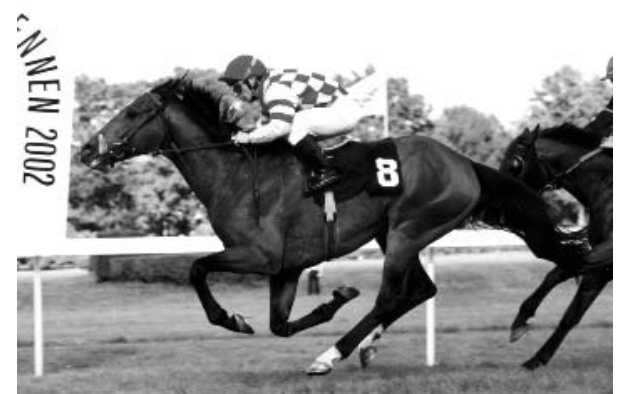

Figure 6 Photograph showing a jockey 3 months after intramedullary nailing of a midclavicular fracture in a contest. 


\section{Take home message}

Elastic stable intramedullary fixation of midclavicular fractures gives athletes the chance of early resumption of training and competition. This operative treatment for midclavicular fractures should be offered to high performance and professional athletes as an alternative to non-operative treatment.

In contrast with intramedullary techniques described so far in the literature, the procedure presented here is based on extended intramedullary stabilisation according to the principle of elastic stable intramedullary nailing as described by Metaizeau. ${ }^{31}$ This results in firm anchorage of the Ti nail within the $S$ shaped clavicle. No implant displacements, refractures, or infections were observed with the 84 fractures treated by this technique.

Because the surgical approach is minimal, it avoids damage to the soft tissues and is not too onerous. Scars are hardly visible. The elastic titanium nail used here is inserted at the sternal end of the clavicle, where the sagittal diameter is at its maximum. ${ }^{32}$ Consequently, there is less risk of perforation of the dorsal cortical bone. Closed reduction manoeuvres were successful in about half of the cases (in the complete set of patients as well as the set of 12 athletes). In the whole group of 84, no injuries of the subclavicular neurovascular bundle or the cupola of the pleura were encountered. The decreased intraoperative risk of such injuries is secondary to the direction of nail implementation (from medial-caudal to lateral cranial). The one disadvantage of the technique is the long duration of $x$ ray fluoroscopy.

Hill et $a l^{33}$ found non-unions in $15 \%$ of his patients. He reported a clear correlation with shortenings of more than $2 \mathrm{~cm}^{33}$ At follow up of 157 patients, Matis et $a^{34}$ found appreciable deterioration of shoulder function in half of the cases, showing clavicular shortening of $1 \mathrm{~cm}$; in cases in which clavicular shortening was $2 \mathrm{~cm}$ or more deterioration was considerable. Therefore correction of the potential shortening of the clavicle is not only a prerequisite for a good cosmetic outcome, but also for rapid bone healing and free movement of the shoulder. The procedure presented here achieves linear compensation of the shortened clavicle, and the symmetry of the shoulder girdle can thereby be restored. Osseous healing with the use of this technique is successful. Stabilisation of the fracture results in quick pain relief, so that immediately after surgery the arm of the shoulder joint concerned can be lifted above the horizontal and may be used in activities of daily living. This gives sporting patients the benefit of early return to training and competition. All 12 athletes in this study resumed their training programmes within one week of surgery.

\section{EXAMPLES OF PATIENTS STUDIED}

(1) At the end of the season, a 13 year old boy had a fall during a motocross competition. Figures 1-4 show the typical series of radiographs. One week after the operation, he resumed training on his motor cycle. In the second postoperative week, he participated in a competition, and, in the third week, he won his division (fig 5).

(2) A rower, aged 26, fell while carrying out fitness training on a bicycle. Seven days after the operation, he began rowing. Four months later, in summer 1998, he and his team won the World Championship in Cologne, Germany.

(3) A jockey, aged 26, fell from his horse during a flat race and suffered a midclavicular fracture. Two weeks after the operation he started riding again, after three weeks he resumed daily training routine, and after two months he won his first race (fig 6). In the first year after injury he won 11 races.

\section{Authors' affiliations}

A Jubel, University Hospital of Cologne, Cologne, Germany

J Andemahr, H Bergmann, A Prokop, K E Rehm, University of Cologne

\section{REFERENCES}

1 Kocher MS, Watters PM, Micheli $\amalg$. Upper extremity injuries in the paediatric athlete. Sports Med 2000;30:117-35.

2 Stanley D, Trowbridge EA, Norris SH. The mechanism of clavicular fracture. A clinical and biomechanical analysis. J Bone Joint Surg [Br] 1988;70:461-4.

3 Jeys LM, Cribb G, Toms AD, et al. Mountain biking injuries in rural England. Br J Sports Med 2001;35:197-9.

4 Kocher MS, Feagin JA, Jr. Shoulder injuries during alpine skiing. Am J Sports Med 1996:24:665-9.

5 Steinbruck K. Sports injuries and sports damage of the shoulder. Unfallchirurg 1986;89:402-8.

6 Nordqvist A, Petersson C. The incidence of fractures of the clavicle. Clin Orthop 1994:300:127-32.

7 Nowak J, Mallmin H, Larsson S. The aetiology and epidemiology of clavicular fractures. A prospective study during a two-year period in Uppsala, Sweden. Injury 2000;31:353-8.

8 Allman FL, Jr. Fractures and ligamentous injuries of the clavicle and its articulation. J Bone Joint Surg [Am] 1967;49:774-84.

9 Rowe CR. An atlas of anatomy and treatment of midclavicular fractures. Clin Orthop 1968:58:29-42.

10 Effenberger T. [Clavicle fractures: treatment, follow-up studies]. Chirurg 1981;52:121-4

11 Eskola A, Vainionpaa S, Myllynen P, et al. Outcome of clavicular fracture in 89 patients. Arch Orthop Trauma Surg 1986;105:337-8.

12 Jubel A, Andermahr J, Schiffer G, et al. The technique of elastic-stable intramedullary nailing of midclavicular fractures. Unfallchirurg 2002;105:511-16.

13 Huskisson EC. Measurement of pain. Lancet 1974;2:1127-31.

14 Constant CR. A clinical method of functional assesment of the shoulder. Clin Orthop 1987;214:160-4.

15 Schmit-Neuerburg KP, Weiss $\mathrm{H}$. [Conservative therapy and treatment results in clavicular fractures]. Hefte Unfallheilkd 1982;160:55-75.

16 McKoy BE, Bensen CV, Hartsock LA. Fractures about the shoulder: conservative management. Orthop Clin North Am 2000;31:205-16.

17 Herbsthofer B, Schuz W, Mockwitz J. [Indications for surgical treatment of clavicular fractures]. Aktuelle Traumatol 1994;24:263-8.

18 Ali Khan MA, Lucas HK. Plating of fractures of the middle third of the clavicle. Injury 1978;9:263-7.

19 Kuner EH, Schlickewei W, Mydla F. [Surgical therapy of clavicular fractures, indications, technic, results]. Hefte Unfallheilkd 1982;160:76-83.

20 Bostman O, Manninen M, Pihlajamaki H. Complications of plate fixation in fresh displaced midclavicular fractures. J Trauma 1997;43:778-83.

21 Bronz G, Heim D, Pusterla C, Heim U. [Osteosynthesis of the clavicle (author's transl)]. Unfallheilkunde 1981;84:319-25.

22 Poigenfurst J, Rappold G, Fischer W. Plating of fresh clavicular fractures: results of 122 operations. Injury 1992;23:237-41.

23 Küntscher G, Maatz. Technik der Marknagelung. Leipzig: Thieme Verlag, 1945.

24 Neviaser RJ, Neviaser JS, Neviaser TJ. A simple technique for internal fixation of the clavicle. A long term evaluation. Clin Orthop 1975;109:103-7.

25 Schwarz N, Leixnering M. [Technic and results of clavicular medullary wiring]. Zentralb/ Chir 1986;111:640-7.

26 Niemeier U, Zimmermann HG. [Kuntscher's open intramedullary nailing of the clavicle. An alternative in the treatment of an old clavicular fracture]. Chirurg 1990;61:464-6.

27 Ngarmukos C, Parkpian V, Patradul A. Fixation of fractures of the midshaft of the clavicle with Kirschner wires. Results in 108 patients [see comments]. $J$ Bone Joint Surg [Br] 1998;80:106-8.

28 Grassi FA, Tajana MS, D'Angelo F. Management of midclavicular fractures: comparison between nonoperative treatment and open intramedullary fixation. J Trauma 2001;50:1096-100.

29 Leppilahti J, Jalovaara P. Migration of Kirschner wires following fixation of the clavicle: a report of 2 cases. Acta Orthop Scand 1999;70:517-19.

30 Schwarz N, Leixnering $M$. [Failures of clavicular intramedullary wire fixation and their causes]. Aktuelle Traumatol 1984;14:159-63.

31 Metaizeau J-P. Osteosynthese chez l'enfant, 1 st ed. Montpellier: Sauramps Medical, 1988.

32 Moseley HF. The clavicle: its anatomy and function. Clin Orthop 1968:58:17-27.

33 Hill JM, McGuire MH, Crosby LA. Closed treatment of displaced middle-third fractures of the clavicle gives poor results [see comments]. J Bone Joint Surg [Br] 1997;79:537-9.

34 Matis N, Kwasny O, Gaebler C, et al. Effects of clavicle shortening after clavicle fracture. Hefte zu der Unfallchirurg 1999;275:314-15. 


\section{COMMENTARY}

This is an interesting extension of the concept of flexible intramedullary nailing to early stabilisation of clavicular fractures in sportsmen. These injuries are seen very commonly in National Hunt jockeys in this country, most of whom return to race riding well before the fracture has consolidated. Whether they have further problems usually depends on the occurrence of an early further fall on the affected shoulder girdle after return to riding. It would be a source of concern if the athlete/jockey sustained further direct trauma to the shoulder girdle before the fracture consolidated. However, the technique does seem a satisfactory and minimally invasive means of rapid restoration of shoulder girdle function in these fractures.

M Foy Consultant Orthopaedic Surgeon, Ridgeway Hospital, Swindon, UK; mafoyfrcs@btinternet.com

\section{$\mathrm{ECHO}$}

\section{Rhabdomyolysis has many causes including severe or unaccustomed exercise}

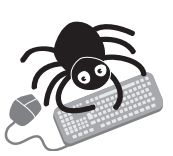

Please visit the British Journal of Sports Medicine website [www. bjsportmed. com] for a link to the full text of this article. habdomyolysis means a breakdown of striated muscle, allowing myoglobin, muscle enzymes, potassium, and other intracellular constituents to leak in to the blood. It has a long and varied list of causes including infections, drugs (including statins), trauma, reperfusion injury, and genetic myopathies. Rhabdomyolysis has also been reported in athletes, particularly long distance runners and body builders. Severe or unaccustomed exercise in high temperatures is particularly risky for polo ponies and race horses as well as humans. In severe cases, the resulting hyperkalaemia, hypocalcaemia and renal failure can be fatal. Milder rhabdomyolysis is easy to miss because the tell tale physical sign-severe myoglobinuria causing tea coloured urine-occurs only after $100 \mathrm{~g}$ muscle has been destroyed. Once recognised, the aim of treatment is to protect renal function (myoglobin is a renal toxin) and restore normal plasma biochemisty, especially potassium. Intravenous saline and sometimes mannitol are used to expand the intravascular volume and increase urine output to more than $200 \mathrm{ml} / \mathrm{hr}$. Frequent monitoring of plasma biochemistry is essential. If acute renal failure ensues despite these measures, continuous haemofiltration or haemodialysis may be required until renal function recovers. There are no randomised trials evaluating the management of rhabdomyolysis. But the fundamental principles have been agreed by consensus. Prognosis is excellent for uncomplicated cases once the cause has been identified, and reversed wherever possible.

A British Medical Journal 2003;327:115-116. 